\title{
Zum Geleit
}

Das vorliegende Buch gibt die erste gedruckte Gesamtdarstellung der ältesten Geschichte der polnischen Länder in deutscher Sprache. Es soll einerseits ein Bild von den grundlegenden Veränderungen zeichnen, die sich während der Frühzeit auf dem Boden Polens vollzogen haben, und andererseits über die Arbeitsergebnisse der polnischen Archäologen in den Jahren nach dem zweiten Weltkrieg berichten.

Das Erscheinen des Buches in der Deutschen Demokratischen Republik zeugt von den freundschaftlichen Verbindungen, die zwischen unseren beiden Ländern bestehen. Die dargestellten geschichtlichen Zusammenhänge beruhen auf umfangreichen Analysen archäologischer Quellen; sie waren und sind Gegenstand von wissenschaftlichen Diskussionen nicht nur in der Volksrepublik Polen, sondern auch in der DDR. Es ist selbstverständlich, daß ich in strittigen Fragen auch anderen auf Quellen sich gründenden Meinungen meine Achtung zolle und, wo immer es möglich ist, die Vielfalt der herrschenden Anschauungen zu der einen oder anderen Frage zur Sprache bringe.

Die Herausgabe meines dritten Buches in deutscher Sprache verdanke ich meinen Freunden und Kollegen in der DDR, besonders dem Direktor des Zentralinstituts für Alte Geschichte und Archäologie, Herrn Professor Dr. Joachim Herrmann.

Möge es wie die anderen zur Kenntnis der frühen Geschichte unserer Länder und zur Entwicklung der freundschaftlichen Beziehungen zwischen ihnen beitragen.

Warschau, den 4. 12. 1973

Witold Hensel 
